\title{
Ligand-gated ion channel interacting proteins and their role in neuroprotection
}

\author{
Shupeng Li, Albert H. C. Wong and Fang Liu* \\ Campbell Family Mental Health Research Institute, Centre for Addiction and Mental Health, University of Toronto, Toronto, ON, Canada
}

\section{Edited by:}

Gerald Zamponi, University of

Calgary, Canada

Reviewed by:

Laurent Fagni, University of

Montpellier, France

Stephen Ferguson, Western,

Canada

*Correspondence:

Fang Liu, Centre for Addiction and Mental Health, 250 College Street

Toronto, ON M5T 1R8, Canada

e-mail: fang.liu@camh.ca
Ion channel receptors are a vital component of nervous system signaling, allowing rapid and direct conversion of a chemical neurotransmitter message to an electrical current. In recent decades, it has become apparent that ionotropic receptors are regulated by protein-protein interactions with other ion channels, G-protein coupled receptors and intracellular proteins. These other proteins can also be modulated by these interactions with ion channel receptors. This bidirectional functional cross-talk is important for critical cellular functions such as excitotoxicity in pathological and disease states like stroke, and for the basic dynamics of activity-dependent synaptic plasticity. Protein interactions with ion channel receptors can therefore increase the computational capacity of neuronal signaling cascades and also represent a novel target for therapeutic intervention in neuropsychiatric disease. This review will highlight some examples of ion channel receptor interactions and their potential clinical utility for neuroprotection.

Keywords: ligand-gated ion channels, protein-protein interaction, receptor complex, glutamate receptors, dopamine receptors
Efficient neurotransmission requires the precise interplay of various neurotransmitter receptors at pre- and post-synaptic compartments. Ligand-gated ion channels play a central role in intercellular communication in the nervous system. Ion channels are the cellular machinery for ion flux across the membrane and therefore the basis of electrical excitation of neurons. Ligandgated ion channels are oligomeric protein assemblies that convert a chemical signal into an ion flux through the post-synaptic membrane, and are involved in basic brain functions such as attention, learning, and memory (Ashcroft, 2006). This paper will review some interactions between ionotropic receptors and other proteins that affect signaling, metabolism, and trafficking. We will detail some of the interactions between G-protein coupled receptors and ion channels, ion channels with intracellular proteins, and ion channels with other ion channels. Specifically, we will discuss how these receptor-protein interactions may help to understand pathology of the nervous system, and offer the hope of new treatment targets for neuropsychiatric disease.

Most eukaryotic membrane channels are composed of several subunits. Pentameric ligand-gated ion channels have five subunits arranged in a pseudosymmetric rosette around the centrally located ion channel pore. Each subunit consists of an extracellular domain that contains the ligand-binding site and a transmembrane ion-pore domain (Kozuska and Paulsen, 2012). The agonist binding site is located at the boundary between subunits in the extracellular domain whereas the ion pore is formed by the transmembrane helices M2, which differentiate axial cationic and anionic channels (Dacosta and Baenziger, 2013).

The modular construction of ionotropic receptors increases the diversity of ligand binding and ion selectivity through the mixing and matching of various subunits (Rojas and Dingledine, 2013). Various other proteins are involved in controlling the type and position of particular subunits in a given channel, as well as the function of the function of the assembled channel. Thus, the function of many receptor proteins can only be fully understood in the context of their interactions with other proteins, the "interactome" (Li et al., 2013a). Through this extensive protein network, the binding of agonist to an ionotropic receptor can exert effects beyond simple current flow, including gene transcription, cytoskeletal rearrangement, and protein synthesis, degradation and transport.

The ligand-gated ion channel superfamily includes nicotinic acetylcholine receptors (nAChRs), adenosine triphosphate (ATP) receptors, $\gamma$-aminobutyric acid (GABA), glutamate, glycine, and 5-hydroxytryptamine (5-HT) receptors (Dent, 2010). The "Cys-loop" sub-family includes the ionotropic receptors for nicotine, GABA, glycine, and 5-HT. "Pore-loop" channels include inwardly-rectifying potassium channels and the glutamate receptors of the AMPA ( $\alpha$-amino-3-hydroxy-5-methyl4-isoxazolepropionic acid) subtype and NMDA (N-methyl-Daspartate) receptors (Connolly and Wafford, 2004). The structure and basic features of several important ion channel types is briefly reviewed below to provide some background, before discussing ion channel interactions with other proteins.

AMPA receptors are the major mediator of fast excitatory synaptic transmission in the mammalian central nervous system. Most of these ionotropic glutamate receptors are permeable to calcium and other cations, thus facilitating depolarization of the cell membrane. AMPA receptors contain four subunits, consisting of two dimers formed by combinations of four pore-forming subunits GluA 1-4. GluA 1/2, and GluA 2/3 are the predominant AMPA receptor types (Anggono and Huganir, 2012). Each subunit is an integral membrane protein with an extracellular amino terminal domain, three membrane-spanning domains (M1, M3, and M4), a hydrophobic hairpin domain (M2) that forms the channel pore, and three intracellular domains: Loop1, Loop2, and 
the carboxyl tail. Although the carboxyl tail is crucial for receptor trafficking and function, other intracellular domains also play an important role in the regulation of AMPA receptor trafficking (Rojas and Dingledine, 2013). The pore lining domain also influences the AMPA receptor trafficking, early in the secretory pathway.

NMDA receptors are also ionotropic glutamate receptors permeable to calcium and sodium, and are critical for synaptic plasticity, learning, and memory. These receptors are involved nicotine addiction and neurological disorders such as ischemic stroke (Dingledine et al., 1999; Albensi, 2007). NMDA channel opening is gated by several elements, including the binding of glutamate to the NR2 subunit, a co-ligand glycine which binds to a separate site on the NR1 subunit, and the removal of a magnesium ion block by depolarization. Thus NMDA channels require both agonist stimulation and depolarization of the post-synaptic membrane for current flow, effectively detecting coincident pre- and post-synaptic activation. Like AMPA receptors, NMDA receptors consist of four subunits, two of which are obligatory GluN1 and two which are modulatory GluN2. These subunits are present in various isoforms that in the NR1 subunit are generated by alternative splicing of the GRIN1 gene. The GluN2 subunits are each encoded by different genes and the subunits are named: NR2A, B, C, and D (Durand et al., 1992; Sugihara et al., 1992; Hollmann et al., 1993; Michaelis, 1998). The exact subunit composition of native NMDARs remains unknown, but it has been suggested that native NMDARs in rat hippocampus largely contain NR1/2A subunits. The intracellular C-terminal (Allison et al., 1998) contains potential sites of protein phosphorylation by different kinases, and motifs for interacting with various protein partners.

For pentameric ligand-gated ion channels such as the $\mathrm{GABA}_{\mathrm{A}}$ receptor, each subunit contains an extensive $\mathrm{N}$-terminal extracellular domain and a short extracellular C-terminal sequence containing the ligand binding sites. Structurally, each receptor is composed of four closely-spaced transmembrane domains including the ion channel wall primarily in $\mathrm{M} 2$, and a variable length cytoplasmic loop between M3 and M4. With both the N-terminus and C-terminus of receptor subunits extending outside the cell membrane, the intracellular M3-M4 loop becomes the most important domain interacting with the intracellular environment. The M3-M4 intracellular loop (IL2) contains protein-protein interaction domains involved in regulating synaptic localization and intracellular trafficking (Maksay, 2009). Despite being highly variable in length and amino acid sequence, the IL2 loop usually contains numerous regulatory motifs and binding sites that differ in each subunit isoform. Moreover, this IL2 loop usually contains sites for phosphorylation, palmitoylation, ubiquitination and other modifications that modulate protein interactions and eventually determine the clustering, stability, and function of ligand-gated ion channels.

Within the central nervous system (CNS), nicotine acts on nicotinic receptors (nAChRs) to initiate various physiological and pathological processes at the cellular and circuit level. Similar to the NMDAR, nAChR is also a ligand-gated ion channel receptor with high $\mathrm{Ca}^{2+}$ permeability. The pentameric nAChR has a number of different subtypes, each with individual pharmacological and physiological profiles and a distinct anatomical distribution in the brain (Gotti et al., 2009). There are 11 neuronal nAChR subunits identified in mammals, including eight $\alpha(\alpha 2-\alpha 9)$ and three $\beta$ ( $\beta 2-\beta 4)$. Unlike NMDAR, nAChR can exist as both hetero-metric and homo-metric-assemblies of these subunits (Albuquerque et al., 2009). In rodents, the $\beta 2$ subunit is found throughout the CNS, mostly as part of the $\alpha 4 \beta 2$ heteromeric receptor, which exhibits high affinity for nicotine. The second common AChR isoform is the $\alpha 7$ homopentamer, expressed mainly in the cortex, hippocampus, and limbic areas.

Numerous proteins are known to bind to the different subunits of pentameric ligand-gated ion channel receptors at specific subcellular localizations. These interacting proteins can both modulate ion channel function and influence the localization of the channel in the cell and in the membrane. There are several major categories of proteins that ligand-gated ion channels interact with: G-protein coupled receptors, intracellular proteins, and other ligand-gated ion channels (Kittler and Moss, 2003; Li et al., 2012; Rojas and Dingledine, 2013). We will discuss each of these types of interaction with examples drawn from our previous work.

\section{LIGAND-GATED ION CHANNEL INTERACTIONS WITH G-PROTEIN COUPLED RECEPTORS}

There are several ion channel interactions with G-protein coupled receptors reported by our group, all involving dopamine receptors: D5-GABA (Liu et al., 2000), D1-NMDA (Lee et al., 2002; Pei et al., 2004), and D2-AMPA (Zou et al., 2005).

First discovered in 2000, the interaction between $\gamma$ aminobutyric acid A receptors and the dopamine D5 receptor was one of the earliest examples of interactions between metabotropic and ionotropic receptors (Liu et al., 2000). The $\mathrm{GABA}_{\mathrm{A}}$ receptor is the major inhibitory neurotransmitter receptor that conducts chloride ions, resulting in hyperpolarization of the cell membrane and thus inhibiting neuron depolarization. The second intracellular loop of the $\mathrm{GABA}_{\mathrm{A}} \gamma 2$ (short) receptor subunit binds directly to the carboxy-terminus of the $\mathrm{D} 5$ receptors. This interaction reduces D5 receptor-mediated cAMP accumulation without altering affinity of the D5 for endogenous and experimental ligands. Conversely, activation of D5 receptors reduces $\mathrm{GABA}_{\mathrm{A}}$ currents and this is not dependent on PKC or PKA. Because these two receptors co-localize in hippocampal and cortical neurons, the bi-directional modulation is potentially important for a number of behaviors and brain disorders. A notable feature of this reciprocal modulation is that it is independent of the classical signaling pathways for each individual receptor.

The interaction between the D1 and NMDA receptor involves direct binding between the carboxy termini of the D1 receptor and the NR1-1a and NR2A subunits of the NMDA receptor (Lee et al., 2002). Because there are two interacting components in the NMDA receptor, the functional consequences are more complicated than with the $\mathrm{D} 5-\mathrm{GABA}_{\mathrm{A}}$ interaction. Although the D1-NMDA interaction occurs in the absence of D1 receptor agonist stimulation, the D1 agonist SKF 81297 decreases the amount of D1-NMDA complex. However, the agonist affects only D1-NR1-1a binding, not the D1-NR2A interaction. 
Similar to the D5-GABA $\mathrm{A}$ interaction, D1 agonist stimulation reduces NMDA currents as well as reducing the slope of the current-voltage curve without altering the reversal potential. This decrease in NMDA conductance is accompanied by a reduction in NMDA cell surface expression. It is independent of PKA/PKC pathways and is mediated by the D1 interaction with the NR2A subunit. The D1-NR1-1a interaction mediates neuroprotective effects of D1 receptor activation, and these effects are not dependent on G-protein signaling but rather are dependent on a PI-3kinase mechanism. The proposed model is that agonist activation of D1 receptors promotes dissociation of the D1-NR1-1a interaction, allowing the NR1-1a carboxy tail to bind CaM and PI-3 kinase, thereby initiating protective cellular cascades. Conversely, the $\mathrm{D} 1$ receptor is also regulated by NMDA receptor activation, which increases cell surface D1 receptor expression, and enhances cAMP accumulation in a SNARE-dependent fashion (Pei et al., 2004).

Dopamine D1 receptors also have a direct physical interaction with N-type calcium channels (Kisilevsky et al., 2008). In prefrontal cortex neurons dopamine D1 receptor activation reduced calcium influx through voltage-gated calcium channels, likely through both voltage-dependent G-protein-mediated pathways and through PKA-mediated pathways. The D1-Cav2.2 channel interaction also regulates cell surface expression and distribution of the channel, allowing effective dopaminergic regulation of backpropogating action potentials that are mediated by $\mathrm{N}$-type calcium channels.

\section{LIGAND-GATED ION CHANNEL INTERACTIONS WITH INTRACELLULAR PROTEINS}

The second category of ion channel interactions to be considered is with intracellular proteins. For the GABAA receptor, multiple interacting proteins have been characterized, that play a role in cytoskeletal coupling by gephyrin, radixin, and F-actin and in signaling modulation by RAFT1 and collybistin (Chen and Olsen, 2007). The functional characteristics of this modulation are related to their subcellular localization with receptors. For example, GABARAP, GODZ, and Plicl interact with the intracellular parts of the GABAA receptor, while GRIP1 and gephyrin are localized to sub-membrane and intracellular compartments.

Our group has recently reported an interaction between the N-terminus of the GluR2 sub-unit of the AMPA receptor and glyceraldehyde-3-phosphate dehydrogenase (GAPDH) (Wang et al., 2012; Zhai et al., 2013). GAPDH is a metabolic enzyme that participates in glycolysis and also plays a role in apoptosis (Tarze et al., 2007). AMPA receptor activation by agonist increases formation of the GluR2-GAPDH complex and promotes cellular internalization. Blocking this interaction with a peptide protects cells against glutamatergic excitotoxicity and ischemia-induced neuronal damage. This interaction is therefore of potential clinical interest for the treatment of ischemic stroke or other conditions with neuronal damage.

Another ion channel-protein interaction that has been of interest because of neuroprotective effects is between the PDZ domain of post-synaptic density 95 (PSD95) protein and carboxyl terminus of the NMDA NR2 subunit (Kornau et al., 1995; Niethammer et al., 1996; Cui et al., 2007). This interaction couples NMDA receptor activation to nitric oxide neurotoxicity (Sattler et al., 1999), and disrupting this interaction can protect neurons from excitotoxicity and ischemic brain damage both in vitro and in vivo (Aarts et al., 2002). PSD-95 also interacts with and suppresses the tyrosine kinase Src and attenuates Src-mediated NMDA receptor upregulation (Kalia et al., 2006). Consistent with these findings, inhibitors of PSD-95 also show neuroprotective effects in animal models of stroke (Sun et al., 2008).

While several examples of direct interactions between ion channels and G-protein coupled receptors have been discussed above, these two types of receptors can also exert functional crosstalk through indirect interactions. For example, the presynaptic voltage-gated calcium channels that influence neurotransmitter release are regulated by G-protein activation and protein kinase C-dependent phosphorylation through binding to $G \beta \gamma$ (Zamponi et al., 1997). G-protein modulation of N-type calcium channels also involves syntaxin 1A, a member of the SNARE protein complex responsible for synaptic vesicle fusion during neurotransmitter release (Jarvis et al., 2000). An additional modulator is cysteine string protein or CSP, which also bind to N-type calcium channels in conjunction with G-proteins to exert a tonic inhibition of the channel (Magga et al., 2000). In the case of G-protein activation in inwardly-rectifying potassium channels (GIRK), the G $\beta \gamma$ directly gates ion channel opening by binding to the intracellular pore of the channel (Nishida and MacKinnon, 2002).

\section{LIGAND-GATED ION CHANNEL INTERACTIONS WITH OTHER ION CHANNELS}

Ion channel receptors can also interact with other ion channels, such as the interaction between the $\alpha 7$ nicotinic acetylcholine receptors and NMDA receptors ( $\alpha 7 \mathrm{nAChR}-\mathrm{NMDA})(\mathrm{Li}$ et al., 2012, 2013b). The carboxy tail of the NMDA receptor NR2 subunit binds directly with the second intracellular loop of the $\alpha 7 \mathrm{nACh}$ receptor, and the interaction promotes ERK1/2 phosphorylation. This interaction is of clinical interest since nicotine increases formation of the complex, and disrupting the $\alpha 7 n A C h R-N M D A$ interaction blocks cue-induced reinstatement of nicotine self-administration in the rat. This behavioral test is a model of relapse in nicotine addiction, suggesting that the $\alpha 7 n A C h R-N M D A$ interaction could be a useful target for novel smoking cessation therapies.

\section{TARGETING LIGAND-GATED ION CHANNEL INTERACTIONS FOR NEUROPROTECTION}

Because of the involvement of ion channel receptors in neuronal death from excitatory glutamate stimulation, there has been considerable interest in these receptors as therapeutic targets for the treatment of brain disorders involving neuronal death, such as ischemic stroke. Ischemic stroke is a major medical problem that affects millions of people world-wide. Current acute post-stroke treatment is focused on lysing the clot obstructing arterial blood flow by using a tissue plasminogen-activator. Due to a very short time window for effectiveness and the potential for intracranial bleeding, few patients can benefit from this treatment (Grossman and Broderick, 2013). Therefore, there is a major need for new 
and safer drugs that can reduce the extent of brain injury from ischemic stroke.

An alternative strategy for post-stroke treatment is to target neurotoxicity instead of focusing on the blood vessel blockade, or in addition to clot lysis. However, preventing excitotoxicity is difficult because glutamate receptors have a critical role in many brain functions. AMPA/kainate receptor antagonists such as NBQX or MPQX can reduce neurological deficits in animal models of autoimmune damage (Smith et al., 2000), but these drugs are too toxic for clinical use. Other strategies, such as blocking the glycine site of the NMDA receptor for treating ischemic stroke have been ineffective in improving outcomes (Lees et al., 2000; Sacco et al., 2001).

The interactions between ionic glutamate receptors and other proteins such as GluR2-GAPDH and NR2-PSD-95 can improve cell survival after ischemic insults, and thus represent another approach to neuroprotective treatments after stroke (Sattler et al., 1999; Zhai et al., 2013). This strategy is attractive because the basic signal transducing functions of the channels are not blocked as they would be by a conventional antagonist. Thus, a more subtle modulation of ion channel function can be achieved, with the hope of reducing excitotoxicity while sparing normal neurotransmission. Those in vitro and animal model experiments used small interfering peptides to disrupt the channel-protein interactions, but these peptides may not be ideal for human clinical use. Therefore, an important priority for future research is the development of suitable drugs targeting the ion channel-protein interactions involved in excitotoxicity.

In summary, ion channel function is modulated by interactions with other proteins. Various proteins influence the number and position of particular subunits in the assembled channel, the dynamics of receptor trafficking and targeting to designated subcellular areas, as well as the assembly, stability, and turnover of the receptor on the membrane and in intracellular signaling pathways. These interactions permit the function of ion channels to be fine-tuned according to both external stimuli and intracellular states. This network of molecular interactions allows for complex signal processing by neurons and also reveals new targets for pharmacological manipulation of neuron function that may be clinically useful. Knowledge of ion channel interactions has progressed rapidly and more such interactions are likely to emerge.

\section{REFERENCES}

Aarts, M., Liu, Y., Liu, L., Besshoh, S., Arundine, M., Gurd, J. W., et al. (2002). Treatment of ischemic brain damage by perturbing NMDA receptor- PSD-95 protein interactions. Science 298, 846-850. doi: 10.1126/science.1072873

Albensi, B. C. (2007). The NMDA receptor/ion channel complex: a drug target for modulating synaptic plasticity and excitotoxicity. Curr. Pharm. Des. 13, 3185-3194. doi: 10.2174/138161207782341321

Albuquerque, E. X., Pereira, E. F., Alkondon, M., and Rogers, S. W. (2009). Mammalian nicotinic acetylcholine receptors: from structure to function. Physiol. Rev. 89, 73-120. doi: 10.1152/physrev.00015.2008

Allison, D. W., Gelfand, V. I., Spector, I., and Craig, A. M. (1998). Role of actin in anchoring postsynaptic receptors in cultured hippocampal neurons: differential attachment of NMDA versus AMPA receptors. J. Neurosci. 18, 2423-2436.

Anggono, V., and Huganir, R. L. (2012). Regulation of AMPA receptor trafficking and synaptic plasticity. Curr. Opin. Neurobiol. 22, 461-469. doi: 10.1016/j.conb.2011.12.006
Ashcroft, F. M. (2006). From molecule to malady. Nature 440, 440-447. doi: 10.1038 /nature04707

Chen, Z. W., and Olsen, R. W. (2007). GABAA receptor associated proteins: a key factor regulating GABAA receptor function. J. Neurochem. 100, 279-294. doi: 10.1111/j.1471-4159.2006.04206.x

Connolly, C. N., and Wafford, K. A. (2004). The Cys-loop superfamily of ligandgated ion channels: the impact of receptor structure on function. Biochem. Soc. Trans. 32, 529-534. doi: 10.1042/BST0320529

Cui, H., Hayashi, A., Sun, H. S., Belmares, M. P., Cobey, C., Phan, T., et al. (2007). PDZ protein interactions underlying NMDA receptor-mediated excitotoxicity and neuroprotection by PSD-95 inhibitors. J. Neurosci. 27, 9901-9915. doi: 10.1523/JNEUROSCI.1464-07.2007

Dacosta, C. J., and Baenziger, J. E. (2013). Gating of pentameric ligand-gated ion channels: structural insights and ambiguities. Structure 21, 1271-1283. doi: 10.1016/j.str.2013.06.019

Dent, J. A. (2010). The evolution of pentameric ligand-gated ion channels. $A d v$ Exp. Med. Biol. 683, 11-23. doi: 10.1007/978-1-4419-6445-8_2

Dingledine, R., Borges, K., Bowie, D., and Traynelis, S. F. (1999). The glutamate receptor ion channels. Pharmacol. Rev. 51, 7-61.

Durand, G. M., Gregor, P., Zheng, X., Bennett, M. V., Uhl, G. R., and Zukin, R. S. (1992). Cloning of an apparent splice variant of the rat N-methyl-Daspartate receptor NMDAR1 with altered sensitivity to polyamines and activators of protein kinase C. Proc. Natl. Acad. Sci. U.S.A. 89, 9359-9363. doi: 10.1073/pnas.89.19.9359

Gotti, C., Clementi, F., Fornari, A., Gaimarri, A., Guiducci, S., Manfredi, I., et al. (2009). Structural and functional diversity of native brain neuronal nicotinic receptors. Biochem. Pharmacol. 78, 703-711. doi: 10.1016/j.bcp.2009.05.024

Grossman, A. W., and Broderick, J. P. (2013). Advances and challenges in treatment and prevention of ischemic stroke. Ann. Neurol. 74, 363-372. doi: 10.1002/ana.23993

Hollmann, M., Boulter, J., Maron, C., Beasley, L., Sullivan, J., Pecht, G., et al. (1993). Zinc potentiates agonist-induced currents at certain splice variants of the NMDA receptor. Neuron 10, 943-954. doi: 10.1016/0896-6273(93)90209-A

Jarvis, S. E., Magga, J. M., Beedle, A. M., Braun, J. E., and Zamponi, G. W. (2000). G protein modulation of $\mathrm{N}$-type calcium channels is facilitated by physical interactions between syntaxin 1A and Gbetagamma. J. Biol. Chem. 275, 6388-6394. doi: 10.1074/jbc.275.9.6388

Kalia, L. V., Pitcher, G. M., Pelkey, K. A., and Salter, M. W. (2006). PSD-95 is a negative regulator of the tyrosine kinase Src in the NMDA receptor complex. EMBO J. 25, 4971-4982. doi: 10.1038/sj.emboj.7601342

Kisilevsky, A. E., Mulligan, S. J., Altier, C., Iftinca, M. C., Varela, D., Tai, C., et al. (2008). D1 receptors physically interact with N-type calcium channels to regulate channel distribution and dendritic calcium entry. Neuron 58, 557-570. doi: 10.1016/j.neuron.2008.03.002

Kittler, J. T., and Moss, S. J. (2003). Modulation of GABAA receptor activity by phosphorylation and receptor trafficking: implications for the efficacy of synaptic inhibition. Curr. Opin. Neurobiol. 13, 341-347. doi: 10.1016/S09594388(03)00064-3

Kornau, H. C., Schenker, L. T., Kennedy, M. B., and Seeburg, P. H. (1995). Domain interaction between NMDA receptor subunits and the postsynaptic density protein PSD-95. Science 269, 1737-1740. doi: 10.1126/science.7569905

Kozuska, J. L., and Paulsen, I. M. (2012). The Cys-loop pentameric ligand-gated ion channel receptors: 50 years on. Can. J. Physiol. Pharmacol. 90, 771-782. doi: 10.1139/y2012-018

Lee, F. J., Xue, S., Pei, L., Vukusic, B., Chery, N., Wang, Y., et al. (2002). Dual regulation of NMDA receptor functions by direct protein-protein interactions with the dopamine D1 receptor. Cell 111, 219-230. doi: 10.1016/S00928674(02)00962-5

Lees, K. R., Asplund, K., Carolei, A., Davis, S. M., Diener, H. C., Kaste, M., et al. (2000). Glycine antagonist (gavestinel) in neuroprotection (GAIN International) in patients with acute stroke: a randomised controlled trial. GAIN International Investigators. Lancet 355, 1949-1954. doi: 10.1016/S01406736(00)02326-6

Li, K. W., Chen, N., and Smit, A. B. (2013a). Interaction proteomics of the AMPA receptor: towards identification of receptor sub-complexes. Amino Acids 44, 1247-1251. doi: 10.1007/s00726-013-1461-9

Li, S., Li, Z., Pei, L., Le, A. D., and Liu, F. (2012). The alpha7nACh-NMDA receptor complex is involved in cue-induced reinstatement of nicotine seeking. J. Exp. Med. 209, 2141-2147. doi: 10.1084/jem.20121270 
Li, S., Nai, Q., Lipina, T. V., Roder, J. C., and Liu, F. (2013b). alpha7nAchR/NMDAR coupling affects NMDAR function and object recognition. Mol. Brain 6:58. doi: 10.1186/1756-6606-6-58

Liu, F., Wan, Q., Pristupa, Z. B., Yu, X. M., Wang, Y. T., and Niznik, H. B. (2000). Direct protein-protein coupling enables cross-talk between dopamine D5 and gamma-aminobutyric acid A receptors. Nature 403, 274-280. doi: $10.1038 / 35001232$

Magga, J. M., Jarvis, S. E., Arnot, M. I., Zamponi, G. W., and Braun, J. E. (2000). Cysteine string protein regulates $\mathrm{G}$ protein modulation of $\mathrm{N}$-type calcium channels. Neuron 28, 195-204. doi: 10.1016/S0896-6273(00)00096-9

Maksay, G. (2009). Ligand-gated pentameric ion channels, from binding to gating. Curr. Mol. Pharmacol. 2, 253-262. doi: 10.2174/1874467210902030253

Michaelis, E. K. (1998). Molecular biology of glutamate receptors in the central nervous system and their role in excitotoxicity, oxidative stress and aging. Prog. Neurobiol. 54, 369-415. doi: 10.1016/S0301-0082(97)00055-5

Niethammer, M., Kim, E., and Sheng, M. (1996). Interaction between the $\mathrm{C}$ terminus of NMDA receptor subunits and multiple members of the PSD-95 family of membrane-associated guanylate kinases. J. Neurosci. 16, 2157-2163.

Nishida, M., and MacKinnon, R. (2002). Structural basis of inward rectification: cytoplasmic pore of the $\mathrm{G}$ protein-gated inward rectifier GIRK1 at $1.8 \mathrm{~A}$ resolution. Cell 111, 957-965. doi: 10.1016/S0092-8674(02)01227-8

Pei, L., Lee, F. J., Moszczynska, A., Vukusic, B., and Liu, F. (2004). Regulation of dopamine D1 receptor function by physical interaction with the NMDA receptors. J. Neurosci. 24, 1149-1158. doi: 10.1523/JNEUROSCI. 3922-03.2004

Rojas, A., and Dingledine, R. (2013). Ionotropic glutamate receptors: regulation by G-protein-coupled receptors. Mol. Pharmacol. 83, 746-752. doi: $10.1124 / \mathrm{mol} .112 .083352$

Sacco, R. L., DeRosa, J. T., Haley, E. C. Jr., Levin, B., Ordronneau, P., Phillips, S. J., et al. (2001). Glycine antagonist in neuroprotection for patients with acute stroke: GAIN Americas: a randomized controlled trial. JAMA 285, 1719-1728. doi: 10.1001/jama.285.13.1719

Sattler, R., Xiong, Z., Lu, W. Y., Hafner, M., MacDonald, J. F., and Tymianski, M. (1999). Specific coupling of NMDA receptor activation to nitric oxide neurotoxicity by PSD-95 protein. Science 284, 1845-1848. doi: 10.1126/science.284.5421.1845

Smith, T., Groom, A., Zhu, B., and Turski, L. (2000). Autoimmune encephalomyelitis ameliorated by AMPA antagonists. Nat. Med. 6, 62-66. doi: 10.1038/71548
Sugihara, H., Moriyoshi, K., Ishii, T., Masu, M., and Nakanishi, S. (1992). Structures and properties of seven isoforms of the NMDA receptor generated by alternative splicing. Biochem. Biophys. Res. Commun. 185, 826-832. doi: 10.1016/0006-291X(92)91701-Q

Sun, H. S., Doucette, T. A., Liu, Y., Fang, Y., Teves, L., Aarts, M., et al. (2008). Effectiveness of PSD95 inhibitors in permanent and transient focal ischemia in the rat. Stroke 39, 2544-2553. doi: 10.1161/STROKEAHA.107.506048

Tarze, A., Deniaud, A., Le Bras, M., Maillier, E., Molle, D., Larochette, N., et al. (2007). GAPDH, a novel regulator of the pro-apoptotic mitochondrial membrane permeabilization. Oncogene 26, 2606-2620. doi: 10.1038/sj.onc.1210074

Wang, M., Li, S., Zhang, H., Pei, L., Zou, S., Lee, F. J., et al. (2012). Direct interaction between GluR2 and GAPDH regulates AMPAR-mediated excitotoxicity. Mol. Brain 5:13. doi: 10.1186/1756-6606-5-13

Zamponi, G. W., Bourinet, E., Nelson, D., Nargeot, J., and Snutch, T. P. (1997). Crosstalk between $\mathrm{G}$ proteins and protein kinase $\mathrm{C}$ mediated by the calcium channel alphal subunit. Nature 385, 442-446. doi: 10.1038/385442a0

Zhai, D., Li, S., Wang, M., Chin, K., and Liu, F. (2013). Disruption of the GluR2/GAPDH complex protects against ischemia-induced neuronal damage. Neurobiol. Dis. 54, 392-403. doi: 10.1016/j.nbd.2013.01.013

Zou, S., Li, L., Pei, L., Vukusic, B., Van Tol, H. H., Lee, F. J., et al. (2005). Protein-protein coupling/uncoupling enables dopamine D2 receptor regulation of AMPA receptor-mediated excitotoxicity. J. Neurosci. 25, 4385-4395. doi: 10.1523/JNEUROSCI.5099-04.2005

Conflict of Interest Statement: The authors declare that the research was conducted in the absence of any commercial or financial relationships that could be construed as a potential conflict of interest.

Received: 14 March 2014; accepted: 21 April 2014; published online: 09 May 2014. Citation: Li S, Wong AHC and Liu F (2014) Ligand-gated ion channel interacting proteins and their role in neuroprotection. Front. Cell. Neurosci. 8:125. doi: 10.3389/ fncel.2014.00125

This article was submitted to the journal Frontiers in Cellular Neuroscience.

Copyright (C) $2014 \mathrm{Li}$, Wong and Liu. This is an open-access article distributed under the terms of the Creative Commons Attribution License (CC BY). The use, distribution or reproduction in other forums is permitted, provided the original author(s) or licensor are credited and that the original publication in this journal is cited, in accordance with accepted academic practice. No use, distribution or reproduction is permitted which does not comply with these terms. 